\title{
Hipertensión pulmonar tromboembólica crónica relacionada con esplenectomía: Reporte de un caso
}

\author{
Chronic Thromboembolic Pulmonary Hypertension \\ related to Splenectomy: A case report
}

\author{
Cándida Rosa Díaz-Brochero ${ }^{1}$, Carlos Eduardo Ruiz Linares ${ }^{2}$, Ana Milena Callejas \\ Gutierrez ${ }^{3}$ Edgar Alberto Sánchez Morales ${ }^{4}$, Alfredo Saavedra Rodriguez ${ }^{5}$.
}

\section{Resumen}

En las últimas décadas se ha sugerido una asociación entre la esplenectomía y el desarrollo de estados protrombóticos. Estos pacientes pueden tener un mayor riesgo de episodios tromboembólicos venosos, incluida la embolia pulmonar. La mayoría de los casos notificados son de pacientes con afecciones hematológicas que pueden ser factores de confusión debido al aumento del riesgo protrombótico. Además, la cirugía después de una lesión abdominal traumática puede ser un factor relevante en el tromboembolismo como complicación médica temprana.

Se presenta el caso de un hombre de 48 años con antecedente de esplenectomía traumática hace 22 años, que acudió al servicio de urgencias con un cuadro de un año de disnea durante el ejercicio, fatiga y presíncope. Durante los últimos dos meses experimentó empeoramiento de la disnea y la tos. La tomografía computarizada con contraste mostró una embolia pulmonar aguda extensa y la ecocardiografía transesofágica mostró un ventrículo derecho dilatado con alta probabilidad de hipertensión arterial pulmonar. Fue dado de alta con warfarina y oxigenoterapia. A los cuatro meses el ecocardiograma mostró persistencia de signos indirectos de hipertensión pulmonar. La gammagrafía de perfusión demostró persistencia de embolia pulmonar en el segmento apical posterior del lóbulo superior izquierdo y segmento apical del lóbulo superior derecho. Fue sometido a cateterismo cardíaco derecho que mostró hipertensión pulmonar tromboembólica crónica. En el seguimiento presentó mejoría de los síntomas. La anticoagulación se continuó indefinidamente. Los pacientes esplenectomizados tienen una mayor incidencia de eventos trombóticos venosos y potencialmente podrían tener un mayor riesgo de desarrollar hipertensión pulmonar tromboembólica crónica.

\begin{abstract}
1 Médica internista Universidad Nacional de Colombia. candidata a magíster en Epidemiología Clínica Universidad Javeriana. Clínica Marly, Hospital Universitario Nacional de Colombia.

${ }_{2}$ Médico internista Universidad Nacional de Colombia. Clínica पDD Cafam Calle 51.

${ }^{3}$ Médica internista y neumóloga Universidad Nacional de Colombia. Neumóloga del Instituto Nacional de Cancerología. Docente ocasional Universidad Nacional de Colombia. ${ }^{4}$ Médico especialista en Medicina Interna Universidad el Bosque. Neumólogo del Instituto Nacional de Cancerología. Profesor asociado de Medicina y neumología de la Universidad Nacional de Colombia.

${ }^{5}$ Médico especialista en Medicina Interna Universidad el Bosque. Neumólogo del Instituto Nacional de Cancerología. Profesor titular Universidad Nacional de Colombia.
\end{abstract}

Correspondence author Cándida Díaz-Brochero MD. Correo electrónico: cdiazbr@unal.edu.co; candidadiaz93@gmail.com 
Palabras clave: Esplenectomía; traumatismo abdominal; embolia pulmonar; tromboembolismo venoso; hipertensión pulmonar; anticoagulantes

\begin{abstract}
Over the last decades, an association between splenectomy and the development of prothrombotic states has been suggested. These patients may be at increased risk for venous thromboembolic events, including pulmonary embolism. Nevertheless, most reported cases are from patients with hematologic conditions, which may be confounding factors because of these patients' increased prothrombotic risk. Additionally, surgery after a traumatic abdominal injury may be relevant with thromboembolism as an early medical complication.

A 48-year-old man with a medical history of traumatic splenectomy 22 years ago presented to the emergency department with a one-year history of shortness of breath during exercise, fatigue, and presyncope. For the last two months, he experienced worsening dyspnea and dry cough. Hours prior to admission, he presented a syncopal event. A contrast-enhanced computed tomography showed extensive acute pulmonary embolism, and transesophageal echocardiography demonstrated a dilated right ventricle with a high probability of pulmonary arterial hypertension. He was discharged with warfarin and home-oxygen therapy. Four months later, an echocardiogram was performed, showing persistence of indirect signs of pulmonary hypertension. Perfusion scintigraphy demonstrated persistence of pulmonary embolism in the posterior apical segment of the left upper lobe and apical segment of the right upper lobe. The patient underwent right heart catheterization that showed chronic thromboembolic pulmonary hypertension. In the follow-up, he presented improvement of referred symptoms. Anticoagulation continued indefinitely.

Splenectomized patients have an increased incidence of venous thrombotic events and could potentially be at greater risk of developing chronic thromboembolic pulmonary hypertension.
\end{abstract}

Keywords: Splenectomy; abdominal injury; pulmonary embolism; venous thromboembolism; pulmonary hypertension; anticoagulants

\section{Introduction}

Splenectomy is a procedure performed for various indications, including benign hematologic conditions (mainly immune thrombocytopenia and hemolytic anemia), cancer, and trauma (life-threatening hemorrhage or severe splenic injury) (1-3). Its related medical complications can be classified as acute and delayed according to the temporality of onset. The firsts include those related to the surgery itself, such as impaired wound healing, bleeding, post-surgical infection, or gastric or pancreatic fistulas (4). On the other hand, delayed complications comprise an elevated risk for cardiovascular and thromboembolic events, including portal-splenic mesenteric venous thrombosis (PSMVT), pulmonary embolism (PE), and deep vein thrombosis (DVT). These events cause significant mortality and morbidity. $(5,6)$

Splenectomy has also been associated with the subsequent development of pulmonary hypertension, potentially leading to chronic thromboembolic pulmonary hypertension (CTEPH), right heart failure, and death. The predisposing causal mechanisms are still incompletely understood. However, some factors such as significant enrichment of anion phospholipids, platelet-derived microparticles, and the retention of abnormal red blood cells in the peripheral circulation may lead to the coagulation cascade's activation and development of thromboembolic events and potentially CTEPH. (7)

Here we present a case of a male patient who underwent splenectomy after penetrating trauma and subsequently developed PE and CTEPH. It is quite striking that the symptoms referred appeared more than 20 years after the splenectomy, without demonstrating other prothrombotic risk factors that could explain the thromboembolic phenomena and chronic pulmonary hypertension present in this case. 


\section{Case presentation}

In our case, a 48-year-old male with a history of surgical splenectomy following penetrating abdominal firearm trauma 22 years ago presented to the emergency department with a one-year history of shortness of breath during exercise, fatigue, weakness, and presyncope, without any other relevant medical, family, genetic, or psychosocial antecedents. Previously, he had consulted another medical institution 4 months after the onset of symptoms. A transthoracic echocardiogram was performed, showing a D-shaped left ventricle secondary to paradoxical interventricular movement due to overload of the right chambers, dilated right atrium and ventricle, with preserved systolic function. Moderate tricuspid regurgitation was also observed -calculated PSAP (systolic pressure in the pulmonary artery) $72 \mathrm{mmHg}$ - with evidence of increased diameter of the inferior vena cava, without inspiratory collapse. Nevertheless, the patient had some difficulties accessing health care during that time, so no treatment was started. Then, for the last two months before admission to our institution, he experienced dyspnea and dry cough deterioration. Hours prior to consulting, he presented a syncopal event. On the physical examination, he was tachypneic, desaturated, with supplemental oxygen requirement through the nasal cannula. Jugular venous distension and hepato-jugular reflux were present. A computed tomography pulmonary angiogram was performed, demonstrating opacification defects in all segmental and some subsegmental branches of the right and left pulmonary circulation (Figure 1).

Also, cardiomegaly at the expense of the right chambers was observed, with an increase in the thickness of the right ventricle of up to $8 \mathrm{~mm}$ and predominant dilation of the right atrium. The right ventricle / left ventricle ratio was 1.18. The pulmonary artery had an increased diameter of up to $35 \mathrm{~mm}$. Taking these findings into account, the patient was considered to have extensive acute PE with the remodeling of the right cavities as a sign of chronic changes due to precapillary pulmonary hypertension. Anticoagulant management with low molecular weight heparins (LMWH) was started, and additional diagnostic workup was made looking for the etiology of PE, including antiphospholipid antibodies and HIV (human immunodeficiency virus) ELISA test. Right heart catheterization was performed, which showed mean pulmonary artery pressure (mPAP) of $43 \mathrm{mmHg}$, pulmonary artery wedge pressure (PAWP) of $14 \mathrm{mmHg}$, with a pulmonary vascular resistance of $7 \mathrm{WU}$ (Wood Unit). With these findings, CTEPH was suspected. The patient had an uneventful hospitalization and was discharged with oral warfarin and bridging therapy with LMWH and home-based oxygen therapy. At the fourth month follow-up, the patient showed an improvement of symptoms, his dyspnea was ranked 2 in the mMRC (modified Medical Research Council) scale, and a therapeutic INR (International Normalized Ratio) was achieved. A new echocardiogram was performed showing persistence of paradoxical interventricular movement, dilated right ventricle, moderate tricuspid regurgitationcalculated PSAP $53 \mathrm{mmHg}$-. With these results, it was decided to order perfusion scintigraphy that showed persistence of PE in the apicoposterior segment of the left upper lobe and apical segment of the right lobe (Figure 2). Anticoagulation continued indefinitely. The patient has manifested significant improvement of dyspnea symptoms in the long-term follow-up without recurrence of pleuritic pain or syncopal events. Referral to a specialized center for pulmonary hypertension is pending.

\section{Discussion}

Venous thromboembolic events (VTE) following splenectomy are not uncommon. The largest cohort study to date with up to 27 years of follow-up evaluated the long-term risks after splenectomy among 8,149 cancer-free American veterans, showing that splenectomized patients had an increased risk of being hospitalized for DVT (Deep Venous Thrombosis) and $\mathrm{PE}$ (rate ratio of 2.2). They also had an increased risk of death due to PE (rate ratio of 4.5). (8)

In another large cohort study, Thomsen et al. (9) demonstrated that compared to the general population and appendectomy subjects, splenectomized patients within the first 90 days after the procedure had a 19.8fold vs 2.3-fold increased risk of DVT and a 32.6-fold vs. the 3.2-fold higher risk of PE respectively. It is worth noting that more than 365 days after splenectomy, the risk diminished but did not disappear, with an adjusted relative risk of 3.7 for DVT and 3.5 for PE.

Although higher rates of VTE (Venous thromboembolism) have been reported in splenectomized patients for hematological or 


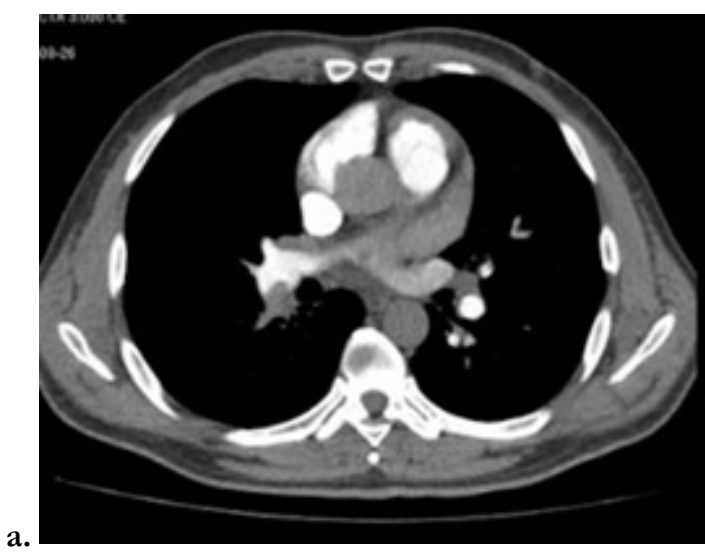

b.
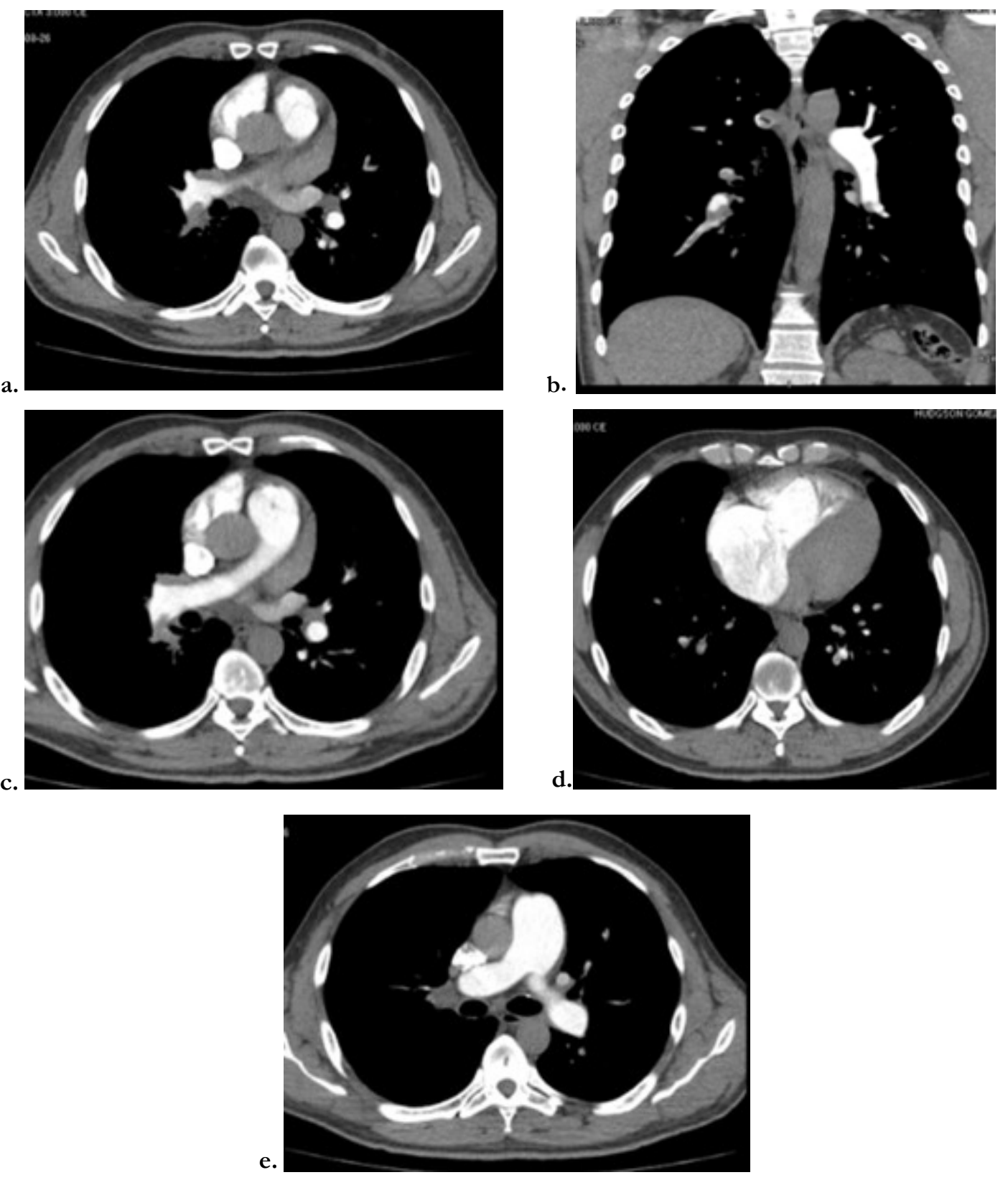

Figure 1. Computed tomography pulmonary angiogram. (a, b, c) Filling defects for the right lower lobe branch extending to segmental and some subsegmental branches of the right and left pulmonary circulation. (d) Cardiomegaly at the expense of the right chambers was observed, with an increase in the thickness of the right ventricle of up to $8 \mathrm{~mm}$ and predominant dilation of the right atrium. (e) The pulmonary artery had an increased diameter of up to $35 \mathrm{~mm}$, consistent with PAH. 
a.

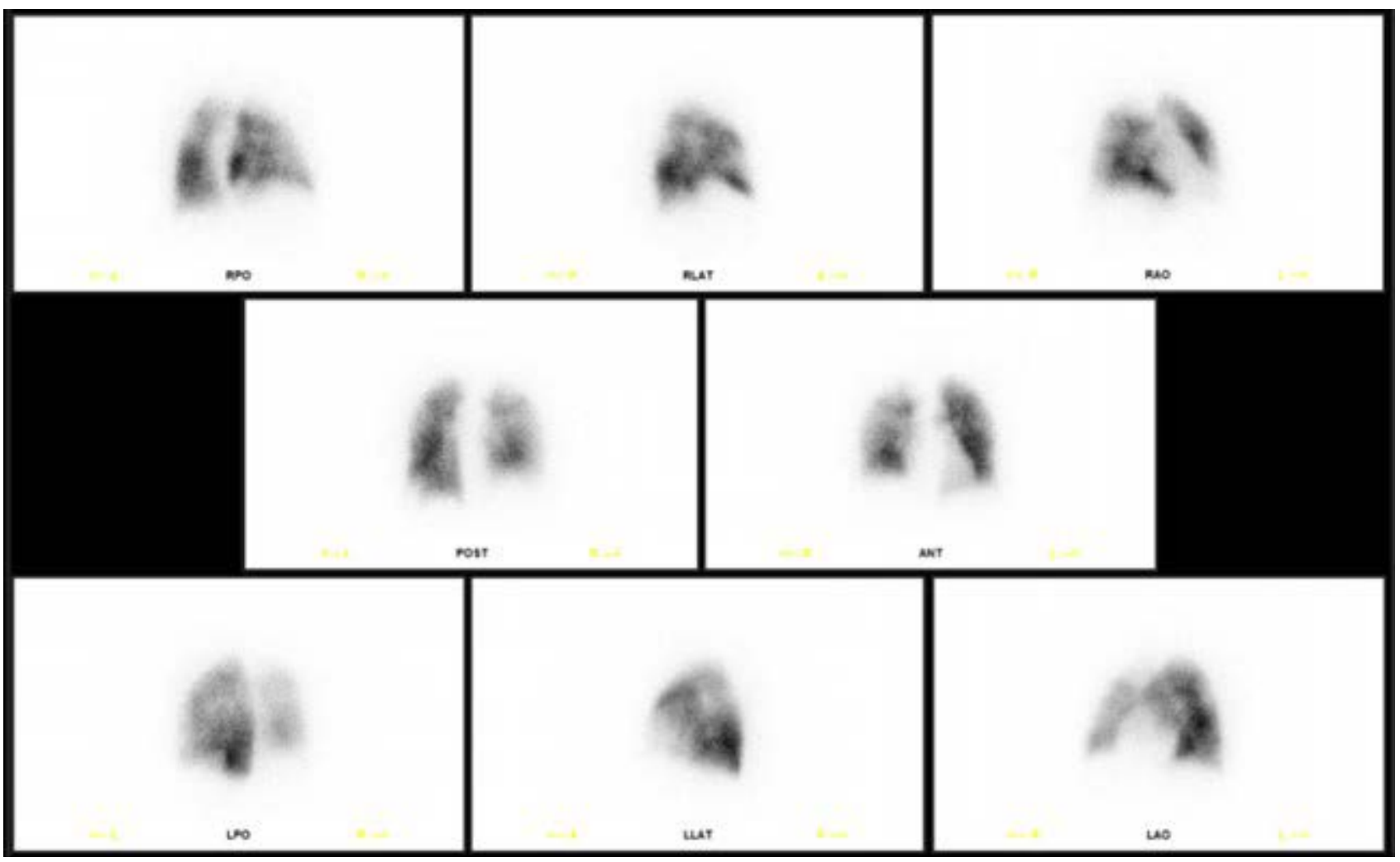

b.

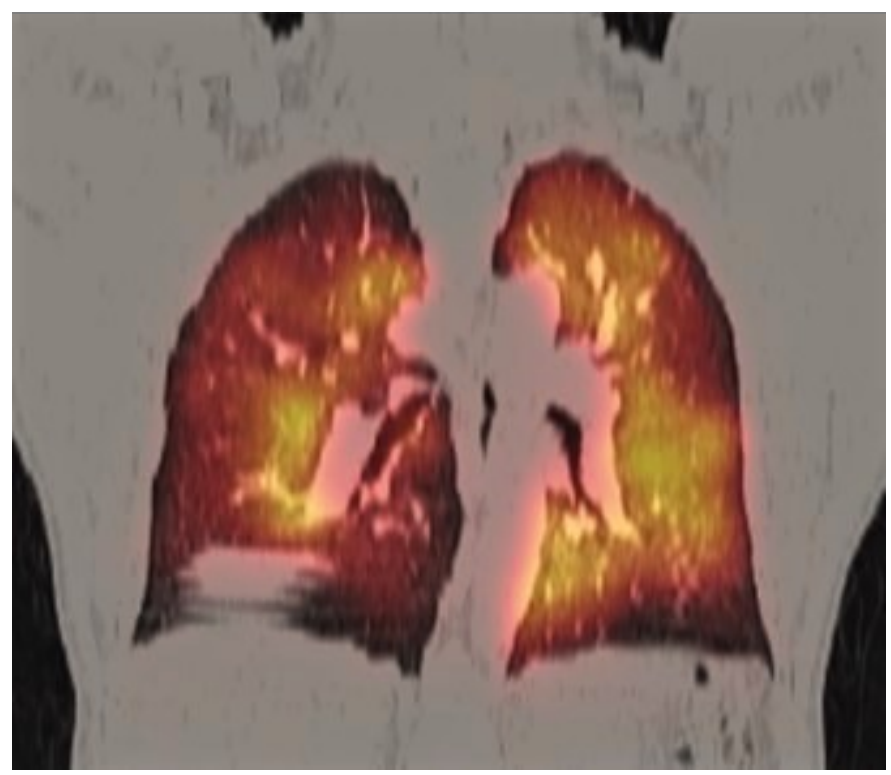

Figure 2. Perfusion scintigraphy. (a). Frontal slices show absence perfusion in the posterior apical segment of the left upper lobe and apical segment of the right lobe. Images acquired include right posterior oblique (RPO), right lateral (RLAT), right anterior oblique (RAO), posterior (POST), anterior (ANT), left posterior oblique (LPO), left lateral (LLAT), left anterior oblique (LAO). (b). Frontal view at the level of interlobar arteries demonstrating diminished perfusion predominantly in the apical segment of the right lobe. 
malignant disorders with splenomegaly compared to trauma patients, the incidence of thrombosis in this group of patients should not be underestimated (5). A retrospective cohort study conducted in Taiwan that included 6,162 splenic injury patients $(3,033$ splenectomized and 3,129 non-splenectomized patients) and 24,648 comparison patients showed that the incidence rates of VTE were 11.81, 8.46, and 5.21 per 10,000 person-years in the splenic injury patients with splenectomy, splenic injury patients without splenectomy, and comparison patients, respectively. These findings contribute to a better understanding of the implied mechanisms of thrombosis in this medical scenario, inferring that the spleen has a role in maintaining coagulation homeostasis and its absence itself constitutes a risk factor for VTE, whether the indication of its removal is a hematological disorder or not, as it is demonstrated in our case.

One late consequence of non-resolution of venous and pulmonary thromboembolism is the development of CTEPH, potentially leading to right heart failure and death. Group IV pulmonary hypertension refers to CTEPH. This condition is defined by the absence of thrombus resolution after one or more episodes of acute pulmonary embolic event, generating a sustained obstruction of the pulmonary arteries and subsequent pulmonary hypertension (7). It has been suggested that disease progression is related to varied factors such as altered vascular remodeling, defective angiogenesis, impaired fibrinolysis, and endothelial dysfunction (10).

World Health Organization (WHO) group IV pulmonary hypertension and WHO group I pulmonary arterial hypertension (PAH) have been demonstrated in patients who have undergone splenectomy for hematologic and non-hematologic reasons (1). A retrospective case-control study conducted by Jais et al. (7) compared the prevalence of splenectomy in patients with CTEPH with patients evaluated during the same period for idiopathic pulmonary hypertension or lung transplantation in other chronic pulmonary conditions. They found that in patients with CTEPH, $8.6 \%$ had a history of splenectomy compared with $2.5 \%$ and $0.56 \%$ in cases of idiopathic pulmonary arterial hypertension and other chronic pulmonary conditions, respectively. Thus, demonstrating that splenectomy may be a potential risk factor developing chronic thromboembolic pulmonary hypertension.

Likewise, another case-control study in a German lung transplant center compared the incidence of splenectomy in patients with idiopathic PAH to the incidence of splenectomy in patients who underwent lung transplantation for other illnesses. The authors found a splenectomy prevalence of $11.5 \%$ in the IPAH group versus a prevalence of $0 \%$ in the group who underwent lung transplantation for other medical reasons. According to pathologic examinations in small pulmonary arteries of patients with CTEPH, it is impossible to correctly differentiate these patients from group I, as they share common histologic features such as intimal fibrosis associated with organized thrombi and recanalization, plexiform lesions, and medial hypertrophy. (11)

Recently, Zhang et al. (12) conducted a systematic review and meta-analysis to explore the association between splenectomy and CTEPH. A total of 6183 participants fulfilled the inclusion criteria. The overall pooled crude prevalence of splenectomy was $4.0 \%$ $(95 \%$ CI 0.03 to $0.06, \mathrm{I} 2=71.5 \%, \mathrm{p}<0.001)$ in patients with CTEPH. Subgroup analysis showed a statistically significant high incidence of splenectomy in patients with CTEPH $(\mathrm{OR}=2.94,95 \% \mathrm{CI} 1.62$ to $5.33, \mathrm{I} 2=0.0 \%$, $\mathrm{p}<0.001)$ compared with patients with pulmonary arterial hypertension. Also, there was a significantly high incidence of splenectomy in patients with CTEPH $(\mathrm{OR}=5.59,95 \% \mathrm{CI} 2.12$ to $14.74, \mathrm{I} 2=0.0 \%, \mathrm{p}<0.001)$ compared with patients with thromboembolic disease (venous thromboembolism or pulmonary embolism). These findings favor the existence of an association of CTEPH with splenectomy.

Although they are not yet fully elucidated regarding the pathophysiological mechanisms that may lead to CTEPH in splenectomized patients, several factors have been proposed that could explain this association. One of the most described responsible mechanisms is post-splenectomy reactive thrombocytosis due to decreased cell degradation. Thrombocytosis normally diminishes years after splenectomy, and the highest rates of VTE occur within the first 90-days post-splenectomy (9). Nevertheless, thrombocytosis alone does not entirely explain the increase in the prothrombotic state in these patients, and its presence is not strictly necessary to develop these complications as they may be present in individuals demonstrating an average platelet count. The increase in VTE following splenectomy may be due to a qualitative defect rather than a quantitative effect of platelet count. (1)

Another described mechanism is hemolysis. 
By releasing free hemoglobin into the circulation, reactive oxygen species are generated, and the enzyme arginase $\mathrm{I}$ is released to the plasma, finally diminishing the bioavailability of nitric oxide, a potent vasodilator. Nitric oxide deficiency can cause endothelial dysfunction and ultimately lead to pulmonary hypertension (13). Hemolysis also results in microparticles development, containing cell surface proteins, intracellular proteins, and genetic material. They originated from the cell membrane of erythrocytes, platelets, and endothelial cells, and their presence has been linked to pro-coagulant effects mainly by the loss of normal membrane symmetry and subsequent phosphatidylserine expression (1). Other described properties of microparticles are the inflammatory modulation and secretion of cytokines and adhesion molecules that may contribute to vascular remodeling and pulmonary hypertension (14). Normally, the spleen is the organ in charge of clearing them from the circulation, so its absence may favor the development of CTEPH in splenectomized patients for hematological and non-hematological causes. (15)

Treatment guidelines recommend that patients with CTEPH be referred to expert centers to confirm a diagnosis and establish of a specific treatment, including pulmonary endarterectomy (PEA) (16). For patients considered candidates for surgical management, PEA is the standard of care as it is potentially curative (17). The number of procedures and experience has steadily increased in the last decade. Around 0.9 PEA procedures per million population are performed annually in the USA and 1.7 per million population in Europe [18]. The hospital mortality rate is low, around 4.7\% in Europe, (19) and it is lower in centers with a high volume of cases. Most patients experience substantial relief of symptoms and almost complete normalization of hemodynamic parameters. (20)

Nevertheless, some patients may be considered inoperable because of several factors such as old age, multiple comorbidities, the presence of distal pulmonary artery obstructions not accessible to surgery, and an imbalance between increased pulmonary vascular resistance and the number of accessible occlusions (21). This population may be offered a percutaneous treatment with balloon pulmonary angioplasty (BPA), associated with improved exercise capacity and hemodynamic parameters in patients with persistent pulmonary hypertension (22). Also, some pharmacologic options may be considered. For example, riociguat (a soluble guanylate cyclase stimulator) is FDA licensed to treat patients with inoperable CTEPH and those with persistent/recurrent CTEPH after PEA (23).

Despite the absence of high-quality evidence from randomized controlled trials (RCT), there is a consensus that lifelong anticoagulation is necessary for CTEPH because of the presence of persistent, organized thrombi that result in pulmonary vasculopathy (24). Direct oral anticoagulants (DOACs) have been increasingly used for CTEPH due to lower bleeding rates and fewer drug interactions. However, DOAC bioaccumulation in CTEPH patients is concerned about the concomitant use of CYP3A inhibitors like type 5-phosphodiesterase inhibitors, hampering their safety benefit (25). Moreover, CYP3A inducers like bosentan may reduce DOAC bioavailability, resulting in reduced efficacy (26).

Some retrospective studies have found similar rates of VTE with rivaroxaban compared with warfarin, with lower bleeding events (27-28), while a small retrospective study found an increased recurrence of VTE with DOACs use (29). A recent systematic review yielded conflicting results regarding VTE recurrence during DOACs use due to study heterogeneity, small sample size, low use of apixaban and dabigatran, and that only observational studies were available (30). High-quality RCTs are needed for evaluating the role of DOACs in CTEPH patients.

\section{Conclusions}

Here we presented a case of a patient with a history of trauma-related splenectomy 22 years ago, who developed non-provoked intermediate-high risk EP, with a past medical history and echocardiographic features suggestive of pulmonary hypertension. Splenectomized patients are exposed to a greater risk of developing VTE and subsequently CTEPH, independent of the indication of its removal. The mechanisms behind promoting a prothrombotic state are yet to be completely elucidated, but the involvement of chronic hemolysis, scavenging of nitric oxide, clearance of microparticles by the spleen, 
and qualitative platelet defects has been suggested. Patients who have undergone surgical splenectomy should be closely monitored for signs and symptoms that guide the appearance of thromboembolic events and pulmonary hypertension. Likewise, it is necessary to consider indefinite anticoagulation for these patients and referral to expert centers for confirmation of diagnosis and treatment, including pulmonary endarterectomy.

Lifelong anticoagulation is indicated in this group of patients, and historically Vitamin $\mathrm{K}$ antagonists (VKAs) were the treatment option. With DOACs currently being the first option for VTE, they have been used in CTEPH patients; however, there is a scarcity of data on safety and efficacy. High-quality RCTs are urgently needed to address this issue.

\section{Acknowledgements}

We thank the radiology team of Hospital Universitario Nacional de Colombia for their help in the interpretation of diagnostic images presented here.

\section{Competing interests}

The authors declare that they have no competing interests

\section{Funding}

Not applicable.

\section{Ethics approval and consent to participate}

As this is a case report, the Hospital Universitario Nacional de Colombia does not require ethics approval. The patient provided written consent to participate in the case report.

\section{Consent to publish}

The patient provided written consent to publish his medical history as well as relevant related workup and diagnostic images, presented in this article. Documentary evidence can be supplied if requested.

\section{Availability of data and materials}

All data generated and analyzed during this study are included in this published article.

\section{References}

1. Kimmig LM, Palevsky HI. Review of the association between splenectomy and chronic thromboembolic pulmonary hypertension. Ann Am Thorac Soc. 2016;13(6):945-54. doi: 10.1513/AnnalsATS.201512-826FR

2. Long B, Koyfman A, Gottlieb M. Complications in the adult asplenic patient: A review for the emergency clinician. Am J Emerg Med. 2021;44:452-457. doi: 10.1016/j. ajem.2020.03.049

3. Lin JN, Chen HJ, Lin MC, Lai CH, Lin HH, Yang $\mathrm{CH}, \mathrm{Kao} \mathrm{CH}$. Risk of venous thromboembolism in patients with splenic injury and splenectomy. A nationwide cohort study. Thromb Haemost. 2016;115(1):176-83. doi: 10.1160/TH15-050381

4. Palkar AV, Agrawal A, Verma S, Iftikhar A, Miller EJ, Talwar A. Post splenectomy related pulmonary hypertension. World J Respirol. 2015;5(2):69-77. doi: $10.5320 /$ wjr.v5.i2.69

5. Rottenstreich A, Kleinstern G, Spectre G, Da N, Ziv E, Kalish Y. Thromboembolic Events Following Splenectomy: Risk Factors, Prevention, Management and Outcomes. World J Surg. 2017;42(3):675-681. doi: 10.1007/s00268017-4185-2

6. Stamou K, Toutouzas K, Kekis P, Nakos S, Gafou A, Manouras A, Krespis E, Katsaragakis S, Bramis J. Prospective Study of the Incidence and Risk Factors of Postsplenectomy Thrombosis of the Portal, Mesenteric, and Splenic Veins. Arch Surg. 2006;141(7):663-669. doi: 10.1001/ archsurg.141.7.663

7. Jais X, Ioos V, Jardim C, Sitbon O, Parent F, Hamid A, et al. Splenectomy and chronic thromboembolic pulmonary hypertension. Thorax. 2005;60(12):1031-4. doi: 10.1136/ thx.2004.038083

8. Kristinsson SY, Gridley G, Hoover RN, Check D, Landgren O. Long-term risks after splenectomy among 8,149 cancer-free American veterans: a cohort study with up to 27 years followup. Haematologica. 2014; 99(2): 392-98. doi: 10.3324/haematol.2013.092460

9. Thomsen RW, Schoonen WM, Farkas DK, Riis 
A, Fryzek JP, Sørensen HT. Risk of venous thromboembolism in splenectomized patients compared with the general population and appendectomized patients: a 10-year nationwide cohort study Thromb Haemost. 2010;8(6):14136. doi: 10.1111/j.1538-7836.2010.03849.x

10. Kim NH, Delcroix M, Jais X, Madani MM, Matsubara $\mathrm{H}$, Mayer $\mathrm{E}$, et al. Chronic thromboembolic pulmonary hypertension. Eur Respir J. 2019; 53: 1801915. doi: 10.1111/j.15387836.2010.03849.x

11. Moser KM, Bloor CM. Pulmonary vascular lesions occurring in patients with chronic major vessel thromboembolic pulmonary hypertension. Chest. 1993;103(3):685-92. doi: 10.1378/ chest.103.3.685

12. Zhang L, Yan P, Yang K, et al. Association between splenectomy and chronic thromboembolic pulmonary hypertension: a systematic review and meta-analysis. BMJ Open. 2021;11:e038385. doi: 10.1136/bmjopen-2020-038385

13. Reiter CD, Wang X, Tanus-Santos JE, Hogg N, Cannon RO, et al. Cell-free hemoglobin limits nitric oxide bioavailability in sickle-cell disease. Nat Med. 2002;8(12):1383-9. doi: 10.1038/ nm1202-799

14. AmabileN, GuignabertC,MontaniD, Yeghiazarians $\mathrm{Y}$, Boulanger CM, Humbert M. Cellular microparticles in the pathogenesis of pulmonary hypertension. Eur Respir J. 2013;42(1):272-9. doi: 10.1183/09031936.00087212

15. Rautou P, Mackman N. Deletion of microvesicles from the circulation. Circulation. 2012;125(13):1601-1604. doi: 10.1161/ CIRCULATIONAHA.112.094920

16. Galie N, Humbert M, Vachiery JL, et al. 2015 ESC/ ERS guidelines for the diagnosis and treatment of pulmonary hypertension: the joint task force for the diagnosis and treat- ment of pulmonary hypertension of the European Society of Cardiology (ESC) and the European Respiratory Society (ERS): endorsed by: association for European Paediatric and Congenital Cardiology (AEPC), International Society for Heart and Lung Transplantation (ISHLT). Eur Respir J. 2016;37(1): 67-119. doi: 10.1093/eurheartj/ ehv317

17. Madani MM. Pulmonary endarterectomy for chronic thromboembolic pulmonary hypertension: state-of-the-art 2020. Pulm Circ. 2021;11(2):20458940211007372. doi:

\section{$10.1177 / 20458940211007372$}

18. Madani MM. Surgical treatment of chronic thromboembolic pulmonary hypertension: pulmonary thromboendarterectomy. Methodist Debakey Cardiovasc J. 2016;12(4):213-218. doi: 10.14797/mdcj-12-4-213

19. Mayer E, Jenkins D, Lindner J, D'Armini A, Kloek J, Meyns B, Ilkjaer LB, Klepetko W, Delcroix M, Lang I, Pepke-Zaba J, Simonneau G, Dartevelle P. Surgical management and outcome of patients with chronic thromboembolic pulmonary hypertension: results from an international prospective registry. J Thorac Cardiovasc Surg. 2011;141(3):702-10. doi: 10.1016/j. jtcvs.2010.11.024

20. Madani MM, Auger WR, Pretorius V, Sakakibara N, Kerr KM, Kim NH, Fedullo PF,Jamieson SW. Pulmonary endarterectomy: recent changes in a single institution's experience of more than 2,700 patients. Ann Thorac Surg. 2012;94(1):97103. doi: 10.1016/j.athoracsur.2012.04.004

21. Pepke-Zaba J, Delcroix M, Lang I, et al. Chronic thromboembolic pulmonary hypertension (CTEPH): results from an international prospective registry. Circulation 2011;124(18): 1973-1981. doi: 10.1161/ CIRCULATIONAHA.110.015008

22. Araszkiewicz A, Darocha S, Pietrasik A, et al. Balloon pulmonary angioplasty for the treatment of residual or recurrent pulmonary hypertension after pulmonary endarterectomy. Int J Cardiol. 2019; 278: 232-237. doi: 10.1016/j. ijcard.2018.10.066

23. Ghofrani HA, D'Armini AM, Grimminger F, et al. Riociguat for the treatment of chronic thromboembolic pulmonary hypertension. N Engl J Med. 2013; 369: 319-329. doi: 10.1056/ NEJMoa1209657

24. Konstantinides SV, Meyer G, Becattini C, et al. 2019 ESC Guidelines for the diagnosis and management of acute pulmonary embolism developed in collaboration with the European Respiratory Society (ERS). Eur Respir J. 2019; 54(3):1901647. doi: 10.1183/13993003.016472019

25. Gabriel L, Delavenne X, Bedouch P et. al. Risk of Direct Oral Anticoagulant Bioaccumulation in Patients with Pulmonary Hypertension. Respiration. 2016;91(4):307-315. doi: 10.1159/000445122

26. Bertoletti L, Mismetti V, Giannakoulas G. Use 
of anticoagulants in patients with pulmonary hypertension. Hamostaseologie 2020;40(3):348355. doi: 10.1055/a-1171-3995

27. Sena S, Bulent M, Derya K et. al. Real-life data of direct anticoagulant use, bleeding risk and venous thromboembolism recurrence in chronic thromboembolic pulmonary hypertension patients: an observational retrospective study. Pulm Circ. 2020;10(1):1-10. doi: 10.1177/2045894019873545

28. Gavilanes F, Alves J, Fernandes C, et al. Use of direct oral anticoagulants for chronic thromboembolic pulmonary hypertension.
Clinics (Sao Paulo). 2018;73:e216. doi: 10.6061/ clinics/2018/e216

29. Bunclark K, Newnham M, Chiu YD, et. al. A multicenter study of anticoagulation inoperable chronic thromboembolic pulmonary hypertension. J Thromb Haemost. 2020;18(1):114-122. doi: 10.1111/jth.14649

30. Sedhom R, Megaly M, Gupta E et. al. Use of direct oral anticoagulants in chronic thromboembolic pulmonary hypertension: a systematic review. J Thromb Thrombolysis. 2021. doi: 10.1007/ s11239-021-02501-8 